\title{
PEMEROLEHAN KALIMAT TANYA BAHASA INDONESIA PADA ANAK USIA DINI
}

\author{
Irma Yulita Silviany \\ Universitas Islam Bandung \\ irma.yulita.s@unisba.ac.id
}

\begin{abstract}
Abstrak
Proses pemerolehan bahasa anak melalui cara yang unik. Pada fase anak usia dini, anak akan terus menggali potensi bahasa dari lingkungan sekitar. Ketika, anak mengajukan pertanyaan, mereka meningkatkan pemahaman mereka tentang suatu hal yang mereka dapatkan dari bertanya, proses berpikir, dan juga keterlibatan mereka dalam percakapan. Selain itu, anak dapat memenuhi kebutuhan anak mengenai informasi dapat mereka tuntaskan dengan bertanya. Anak usia dini dalam penelitian ini khususnya telah mengetahui beragam fungsi bahasa. Salah satu fungsi bahasa yang digunakan oleh anak pada usia dini menurut Halliday ialah fungsi instrumental, yakni penggunaan bahasa untuk memenuhi kebutuhannya. Oleh sebab itu, penelitian ini untuk mendeskripsikan pemerolehan kalimat tanya dalam bahasa Indonesia pada anak usia dini. Jenis penelitian mengaplikasikan metode analisis deskriptif. Data yang ingin diperoleh dalam penelitian ini adalah data berupa kalimat tanya bahasa Indonesia secara komprehensif yang disampaikan oleh anak usia dini. Studi ini mengungkap kemampuan anak usia 5 (lima) tahun telah memperoleh kemampuan dalam menggunakan kalimat tanya melalui berbagai strategi dan pola yang bervariasi tergantung dengan siapa petuturnya. Anak telah mampu melaksanakan untuk pertanyaan 'apa' dan 'mana' atau jika dipadankan dalam bahasa Inggris disebut dengan WH-Questions, serta mampu mengintegrasikannya dalam sebuah kalimat tanya. Anak sudah mampu mengkonfirmasi ulang mengenai suatu informasi yang masih dianggapnya ragu dengan menggunakan kata 'iya kan' dan 'bener kan' dengan intonasi bertanya. Anak usia dini sudah mampu memilah kalimat tanya tergantung dari siapa lawan tuturnya.
\end{abstract}

Kata kunci : pemerolehan bahasa, kalimat tanya, anak usia dini

\section{Pendahuluan}

Berbagai bentuk kalimat diungkapkan oleh anak usia dini dalam aktivitas sehari-hari, layaknya manusia dewasa yang telah memperoleh bahasanya secara utuh. Pengungkapan kalimat oleh anak usia dini guna memenuhi kebutuhan 
hidupnya. Mulai dari menyatakan sesuatu dalam bentuk kalimat berita, meminta, hingga bertanya. Kalimat tanya dilakukan oleh anak guna mengeksplorasi kemampuan diri dan kebutuhan lingkungan. Melalui kalimat tanya menurut Dardjowidjjo (2008), tindak ujaran tanya melalui proses (1) menentukan representasi kalimat yang diucapkan dari yang didengar, (2) mencari dalam memori suatu antesiden yang cocok dengan informasi lama pada kalimat. Ketika anak-anak mengajukan pertanyaan, mereka meningkatkan pemahaman mereka tentang pengetahuan konten, proses berpikir mereka, dan keterlibatan mereka dalam percakapan. Rasa penasaran mendorong anak-anak untuk terlibat dalam pembelajaran mandiri dan keterampilan berpikir tingkat tinggi melalui kalimat tanya.

Proses pemerolehan bahasa, bermula dengan manusia mempunyai apa yang dinamakan faculties of the mind, yakni semacam kapling-kapling intelektual (dan abstrak) dalam benak atau otak mereka. Salah satu dari kapling-kapling ini dijatahkan untuk pemakaian dan pemerolehan bahasa menurut Chomsky dalam Dardjowijojo (2000). Anak belajar memahami makna dan memfungsikan bahasa dalam konversasi. Orang tua mengarahkan anak bagaimana memanfaatkan bahasa untuk berkomunikasi: ketika berada situasi tertentu, ketika dengan mitra tutur yang spesifik atau ketika berbicara tentang topik tertentu. Anak menguasai bahasa dan sekaligus belajar bagaimana bahasa bekerja (ibid. 2012).

Kompetensi pemerolehan bahasa anak mengungkap bagaimana anak mengekspresikan harapan dan pencarian informasi mereka dari lingkungan sekitar atau pun mitra tutur mereka. Pada saat mengajukan pertanyaan, anak sedang melibatkan beberapa keterampilan kognitif, seperti misalnya metakognisi, yaitu kemampuan untuk mencari reflektif melalui memori dan rasa pengetahuan dari sebelumnya, perhatian, fungsi eksekutif, sumber daya (kontrol), serta thery of mind. Perkembangan pada masing-masing kemampuan tersebut memungkinkan keefektifan dan keefisienan anak dalam mencari informasi dengan menggunakan pertanyaan (Ranford, dkk.,2018) 
Seperti yang dikemukakan oleh Ness (2020), para ibu biasanya ditanyai rata-rata 228 pertanyaan setiap hari oleh anak-anak mereka yang berusia dua sampai sepuluh tahun. Pada saat anak-anak mengajukan pertanyaan, mereka sedang mencari kepuasan yang akan dating melalui penemuan atau pemahaman. Hal tersebut menguatkan jika anak usia dini menemukan dan memahami sesuatu hal dari bertanya. Dalam Dardjowijojo (2008), anak memulai berbahasa dengan mengucapkan satu kata (atau bagian kata). Kata ini bagi anak, sebenarnya adalah kalimat penuh. Ketika anak usia dini, sudah dapat mengucapkan kalimat dalam bentuk pertanyaan yang utuh, hal tersebut menunjukkan kemampuan anak dalam mengekplorasi diri dalam berbahasa sudah tinggi. Selain itu, menurut Dardjowijojo, seorang anak yang dapat mengajukan pertanyaan mana/apa sebagai padanan bahasa Inggris WH-Questions dilandasi oleh argumentasi bahwa mana dapat mewakili berbagai macam pertanyaan (di mana, ke mana, bagaimana) dan apa dapat pula mewakili apa, siapa, berapa, kenapa/mengapa. Pertanyaan mana/apa tidak hanya menanyakan benar tidaknya suatu proposisi, tetapi mencari sutau butir informasi tertentu. Melalui pertanyaan mana/apa anak sedang mencari dalam memorinya untuk menemukan butir informasi yang diperlukan.

Pertanyaan menurut Ronfard, dkk. (2018), terdiri dari empat komponen yang melatarbelakanginya, yaitu (1) inisiasi, misalnya ketidaktahuan atau keingintahuan anak yang menjadi dasar sebuah pertanyaan dilontarkan (2) perumusan, pada tahap ini anak mengidentifikasi informasi apa yang akan diminta (3) ekspresi, pemutusan mengenai membagikan pertanyaan kepada mitra tutur (4) evaluasi respon, dimana anak akan menanggapi jawaban atas pertanyaan yang diajukan olehnya, baik itu rasa keingintahuannya mengenai suatu hal telah tuntas atau belum.

\section{Metode Penelitian}

Penelitian ini menggunakan pendekatan kualitatif dengan metode analisis deskriptif. Penelitian ini memfokuskan diri untuk mengeksplorasi kalimat tanya bahasa Indonesia anak sebagai penanya. Partisipan penelitian ini merupakan anak berusia 5 (lima) tahun dengan latar belakang pendidikan orang tua dari lulusan PT 
di konteks lingkungan masyarakat berbahasa Sunda. Bahasa pertama partisipan ialah bahasa Indonesia.

Pemilihan partisipan berdasar pada Dewart dan Summers (1995), serta dari hasil observasi awal bahwa anak usia 5 (lima) tahun telah mampu berkomunikasi dengan cukup baik, mampu pula mengeksplorasi kata menjadi kalimat pertanyaan-pertanyaan untuk menuntaskan rasa penasarannya mengenai suatu hal. Proses pengambilan data dilakukan dengan cara perekaman ketika anak sedang berinteraksi dengan mitra tutur yang berbeda di lingkungannya, yaitu nenek, kakek, orang tua, dan teman.

Hal tersebut dilakukan untuk melihat keragaman dan kemampuan anak dalam mengolah kalimat menggunakan kata tanya yang telah dikuasai anak untuk bertanya.

\section{Hasil Penelitian Dan Pembahasan}

Hasil analisa pemerolehan kalimat tanya bahasa Indonesia pada anak usisa dini merujuk terhadap kerangka kerja yang disusun oleh Ronfard, dkk.(2018) bernama Model of Question Asking, Double arrows represent simultaneous Interactive Processes (uraian pada bagan).

Panduan kerangka kerja tersebut mengungkapkan bahwa kalimat tanya menurut Ronfard, dkk. (2018), terdiri dari empat komponen yang melatarbelakanginya, yaitu (1) inisiasi, misalnya ketidaktahuan atau keingintahuan anak yang menjadi dasar sebuah pertanyaan dilontarkan (2) perumusan, pada tahap ini anak mengidentifikasi informasi apa yang akan diminta (3) ekspresi, pemutusan mengenai membagikan pertanyaan kepada mitra tutur (4) evaluasi respon, dimana anak akan menanggapi jawaban atas pertanyaan yang diajukan olehnya, baik itu rasa keingintahuannya mengenai suatu hal telah tuntas atau belum.

Berikut bagan penjelasan mengenai panduan tersebut. 


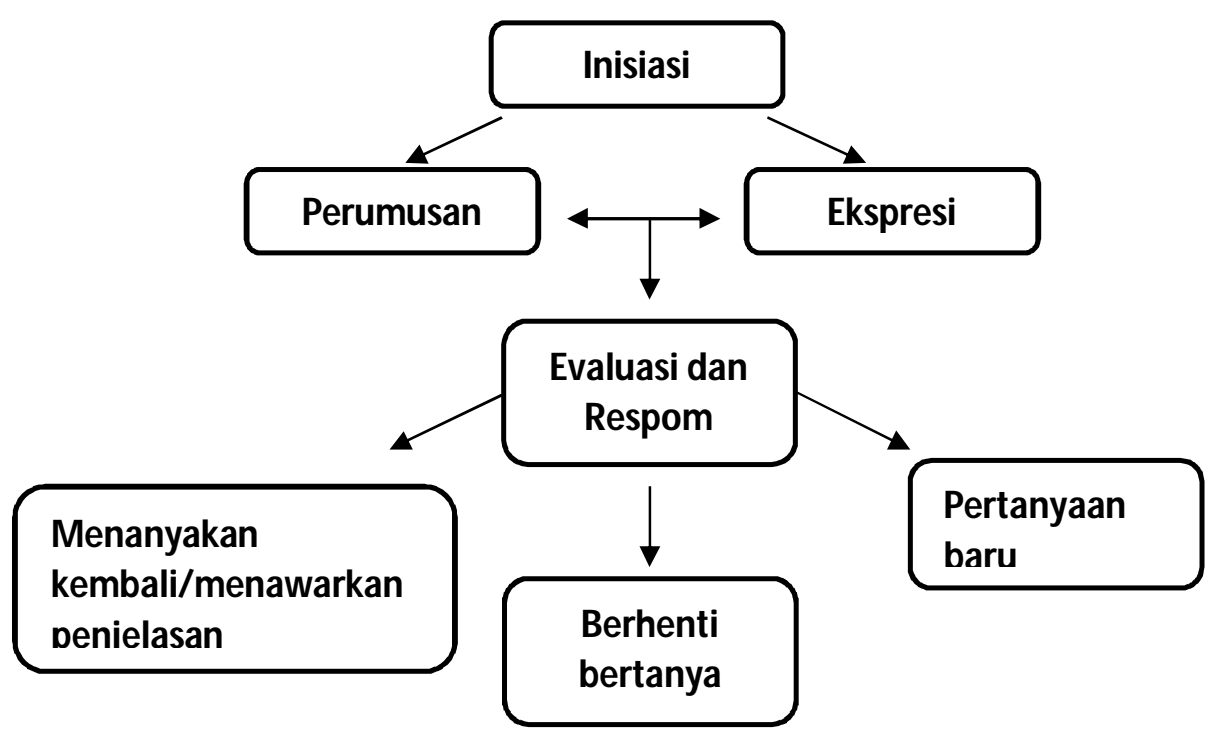

Kalimat tanya bahasa Indonesia yang dilontarkan oleh anak berawal dari tahap pertama adanya inisiasi yang dipicu oleh kesadaran bahwa informasi sangat kurang dan anak membutuhkan informasi tersebut. Tahap kedua perumusan, tahap ini anak mengidentifikasi informasi apa yang harus ditanyakan dalam bentuk pertanyaan sehingga dapat dipahami. Tahap ketiga, respon itu memutuskan mengajukan pertanyaan kepada seseorang. Tahap terakhir adalah evaluasi, yaitu menilai jawaban dan memutuskan apakah informasi yang didapatkan sudah cukup atau masih membutuhkan respon kembali agar informasi yang akan dicapai oleh anak sudah utuh.

\begin{tabular}{|l|l|l|l|}
\hline Inisiasi & Perumusan & Respon & Evaluasi \\
\hline Anak & Mengidentifikasi & Memutuskan & Menilai jawaban \\
membutuhkan & informasi dengan & dengan & lawan tutur, \\
suatu informasi & kalimat tanya apa & mengeluarkan & apakah sudah \\
atau rasa ingin & yang harus & kalimat tanya & cukup memberi \\
tahu anak terhadap & digunakan untuk & & jawaban atau \\
suatu hal & tercapainya tujuan & & memerlukan \\
& pengetahuan suatu & & respon lanjutan \\
\hline
\end{tabular}




\begin{tabular}{|l|l|l|l|}
\hline & informasi & & \\
\hline
\end{tabular}

1. Ayah: Mau beli apa, De?

Anak: Berapaan kalau ini? (nunjuk mainan)

Penjual: Lima ribu, De

(konteks: siang hari saat ikut ibu ke warung)

Tahap Inisiasi anak ingin memiliki mainan
2. Anak: Kenapa water boom-nya belum bangun? (maksud belum selesai pembangunan tempat)

Ibu: Soalnya masih belum selesai dibangun, keliatan tuh masih banyak pegawai bangunan

(konteks: dijalan melewati tempat tersebut)

Tahap respon: anak merespon kalimat atas rasa penasaran terhadap suatu tempat, meskipun masih belum menggunakan imbuhan yang benar dalam kata 'bangun'

4. Anak: Kak, ini maininnya gimana? Kakak: Sama kaya main baby bus, cari jalan sampai akhir

Anak: Kenapa ga bisa maju? Kalau baby bus tinggal digeser iya kan?

(konteks sore hari saat bermain game)

(konteks di toko buku)

Tahap perumusan: anak merumuskan kalimat tanya yang hendak ingin dicapai dengan strategi bertanya dahulu

5. Anak: Aku mau ikut ke tempat

6. Kakak: Liburan nanti pengen 


\begin{tabular}{|c|c|}
\hline kerja nenek? Dimana sih? & kemana, De? \\
\hline $\begin{array}{l}\text { Nenek: Nanti aja sama ibu, jauh } \\
\text { soalnya }\end{array}$ & $\begin{array}{l}\text { Anak: Aku lebih suka ke hotel. } \\
\text { Emang kakak pengen kemana? }\end{array}$ \\
\hline $\begin{array}{l}\text { Anak: Dimana emang? } \\
\text { (Situasi anak ingin ikut kerja }\end{array}$ & $\begin{array}{l}\text { Kakak: Aku juga ke hotel yang ada } \\
\text { kolam renangnya }\end{array}$ \\
\hline kepada neneknya) & Anak: Gimana kesananya kalau ayah \\
\hline $\begin{array}{l}\text { Tahap Evaluasi muncul pada } \\
\text { kalimat tanya yang dilontarkan } \\
\text { oleh anak. Anak melanjutkan } \\
\text { pertanyaan karena belum puas } \\
\text { dengan jawaban yang diberikan } \\
\text { mitra tutur sebelumnya. }\end{array}$ & $\begin{array}{l}\text { kerja? } \\
\text { (situasi sore hari saat sedang main) } \\
\text { Tahap Evaluasi sudah muncul dalam } \\
\text { kalimat tanya ini, anak mengevaluasi } \\
\text { dengan memberikan pertanyaan baru } \\
\text { yang masih berkaitan dengan } \\
\text { pertanyaan sebelumnya. }\end{array}$ \\
\hline
\end{tabular}

Hasil menunjukkan bahwa anak sudah mampu melewati keempat tahapan dalam memproduksi kalimat tanya. Tahap pertama, anak sudah mampu melaksanakan inisiasi, yaitu pemenuhan kebutuhan informasi mengenai suatu hal. Tergambar melalui data bahasa nomor 1 (satu), ketika anak menginginkan sesuatu (dalam konteks percakapan anak menginginkan mainan), anak menanyakan harga mainan kepada penjual. Dalam data bahasa ini anak sudah mampu mengaplikasikan penggunaan kata tanya berapa. Tahap kedua, anak telah melaksakan perumusan, yaitu anak mampu mengidentifikasi informasi apa yang akan ditanyakan dan menyusun pertanyaan agar dapat dipahami dan dijawab oleh mitra tutur. Perumusan telah diperoleh oleh partisipan dalam penelitian ini, terlihat dalam data bahasa nomor 3 (tiga), anak berusaha mengidenfitikasi informasi tentang sesuatu (komik) kosakata yang lupa dan setelah mendapat jawaban yang diinginkan. Anak melanjutkan dengan mengajukan pertanyaan 
sesuai dengan informasi yang ingin diketahui, yaitu perbedaan antara komik dan buku cerita. Meskipun, masih terdapat kesalahan pemilihan diksi pada akhir kalimat tanya, seharusnya 'apa bedanya', anak mengucapkan 'apa isinya'.

Tahap ketiga, anak sudah menghasilkan respon yang baik dalam pemerolehan kalimat tanya dalam bahasa Indonesia. Respon muncul dalam data bahasa nomor 2 (dua), dimana respon adalah hasil dari inisiasi dan perumusan sebelumnya. Anak mampu menghasilkan kalimat tanya yang menggunakan kata tanya kenapa/mengapa, meskipun dari temuan masih belum pemberian imbuhan pada salah satu kata dalam kalimat tersebut, kata 'bangun', seharusnya diberi imbuhan 'dibangun'. Tahap empat, pada tahapan ini merupakan rangkaian paling tinggi dari pemerolehan kalimat tanya. Dimana anak mampu mengevaluasi dari ketiga tahapan sebelumnya. Tahap evaluasi ini yang paling banyak ditemukan, yakni data bahasa nomor 4-6. Tahap evaluasi ini, anak dapat menilai jawaban lawan tutur, ketika anak merasa belum cukup memberi jawaban dan memerlukan respon lanjutan. Respon lanjutan ini berupa pertanyaan ulang atau menegaskan dan memberi pertanyaan baru untuk menuntaskan rasa penasaran anak mengenai suatu informasi.

\section{Simpulan}

Senarai dengan penjelasan sebelumnya, anak sudah mampu melaksanakan keempat tahapan dalam melontarkan kalimat tanya dalam bahasa Indonesia. Pertanyaan mana dan apa (WH-Questions) telah mampu diucapkan oleh anak dalam kalimat tanya untuk memperoleh informasi tertentu. Pada data bahasa anak melewati proses mencocokan informasi lama yang telah tersimpan dalam memori anak dengan informasi baru yang hendak diketahui oleh anak. Anak juga dapat mengenali kata tanya yang sesuai untuk diintegerasikan dalam sebuah kalimat tanya bahasa Indonesia.

Anak sudah mampu menggunakan kata tanya 'gimana' atau bagaimana (digolongkan kata tanya apa) dan kata tanya ' dimana' (digolongkan kata tanya mana), meskipun untuk kata tanya dimana ini anak belum dapat merangkaikan 
dengan kata yang benar. Seperti terlihat pada data bahasa nomor 5, penempatan kata tanya dimana masih diletakkan pada bagian akhir sebuah kalimat. Evaluasi atau tahapan paling akhir dalam pemerolehan kalimat tanya telah banyak diperoleh oleh partisipan dalam penelitian ini. Anak juga sudah mampu menegaskan mengenai informasi yang masih dianggapnya ragu dengan membubuhkan kata ‘iya kan' dan 'bener kan’ untuk menegaskan.

\section{Daftar Pustaka}

Berns, M. 1990. Context of Competence: Social and Cultural Considerations in Communicative Language Teaching. New York: Plenum.

Clark, E.V. 2009. First Language Acquisition. New York: Cambridge University Press.

Clark. E.V. 2004. Pragmatics and Language Acquisition. Handbooks of Pragmatics. Laurence R. Horn dan Gregory Ward (ed.) USA: Blackwell Publishing.

Dardjowidjojo, S. 2000. Echa: Kisah Pemerolehan Bahasa Anak Indonesia. Jakarta: Gramedia Widiasarana.

Dardjowidjojo, S. 2008. Psikolinguistik. Jakarta: Yayasan Obor Indonesia.

Dewart, H \& Summers, S. 1995. The Pragmatics Profile of Everyday Communication Skills in pre -school and school-aged children.Windsor: NFER-Nelson.

Ronfard, Samuel, dkk. 2018. Question-asking in childhood: A review of the literature and a framework for understanding its development. Journal Elsevier.

Ness, Molly. 2020. Kids Ask the Darndest Questions: Raising Curious Children. 